\title{
CRIANÇAS YOUTUBERS E O EXERCÍCIO DO DIREITO À COMUNICAÇÃO
}

\author{
YOUTUBER KIDS AND THE PRACTICE OF THE \\ COMMUNICATION RIGHT
}

\author{
Inês Vitorino Sampaio ${ }^{1, *}$ (iD \\ Georgia C. Pereira² (D) \\ Andrea Pinheiro Paiva Cavalcante ${ }^{3}$ iD
}

\begin{abstract}
RESUMO: Este artigo problematiza o lugar de fala e de expressão da criança no YouTube, sob a ótica dos seus direitos digitais, consubstanciados no direito à proteção, à provisão $\mathrm{e}$ à participação. O estudo tem por base a playlist "Rico vs Pobre", procedendo a uma análise crítica do discurso de cinco vídeos. $\mathrm{O}$ exercício do direito à participação, numa rede marcada pela lógica mercadológica e a pressão pelo reconhecimento público, tem como contraponto o incentivo ao consumismo, à rivalidade entre crianças e à falta de consciência social, revelando o comprometimento dos direitos à provisão e à proteção.
\end{abstract}

Palavras-chave: "Rico vs Pobre”. Crianças YouTubers. Direito à comunicação. Direitos digitais. Participação.

\begin{abstract}
This article aims to discuss the child's place of speech and expression on YouTube, considering their digital rights to protection, provision, and participation. Based on the playlist "Rico vs Pobre" (rich vs. poor), the study conducts a critical discourse analysis of five videos. The exercise of the right to participate, in a network guided by market logic and the pressure for public recognition, brings some compromises to the rights to protection and provision through the encouragement of consumerism, rivalry among children, and lack of social awareness.
\end{abstract}

Keywords: "Rico vs Pobre”. YouTuber kids. Right to communication. Digital rights. Participation.

\footnotetext{
1.Universidade Federal do Ceará - Programa de Pós-graduação em Comunicação - Fortaleza (CE), Brasil. 2.Universidade Federal do Ceará - Curso de Sistemas e Mídias Digitais - Fortaleza (CE), Brasil.

3.Universidade Federal do Ceará - Programa de Pós-graduação em Políticas Públicas - Fortaleza (CE), Brasil.

*Autora correspondente: inesvict@gmail.com

Número temático organizado por: Gilka Girardello, Adriana Hoffmann e Inês Vitorino Sampaio
} 


\section{Introdução}

O reconhecimento de que as crianças são sujeitos de direitos se instituiu como princípio normativo no Brasil com a Constituição de 1988 e o Estatuto da Criança e do Adolescente, em 1990. Tais documentos estabelecem um pacto nacional que reconhece a condição peculiar da criança como pessoa em desenvolvimento e a responsabilidade compartilhada da família, da sociedade e do Estado brasileiros de assegurar, com absoluta prioridade, seus direitos fundamentais. Este artigo aborda alguns desafios atinentes ao exercício de um desses direitos: o direito à comunicação.

Em condição similar à de subalternos, como as mulheres, os negros e outras minorias (SPIVAK, 2010), crianças e adolescentes, na maior parte da história, foram "impelidos" a silenciar e a lidar com os discursos adultos que os nomeavam e imprimiam sentido às suas histórias. Nas últimas décadas, esses lugares de fala vêm sendo, cada vez mais, revisitados e tensionados nas esferas públicas midiáticas. Crianças e adolescentes têm sido, com frequência, enquadrados sob enfoques extremos, que os configuram como objetos de amor ou de ódio. No plano discursivo, assumem a condição de "objeto da paparicação pública" (p. ex., "mini-celebridades", "garotos-propaganda", "meninos-prodígio") ou de ameaça à sociedade (p. ex., "menores", "delinquentes", "vagabundos"), classificados como merecedores de proteção ou de práticas de extermínio. No entremeio desses enquadramentos, crianças e adolescentes buscam se fazer ouvir, na concretude de suas experiências diversas, quase sempre com menor visibilidade.

Sob a égide da radiodifusão, a presença da criança e/ou do adolescente tende a ser, em regra, viabilizada, com a autorização prévia de pessoas adultas. Sua participação depende de uma série de autorizações, que podem incluir os pais e/ou responsáveis, profissionais de comunicação, juízes etc. A própria dinâmica da participação infantil, quanto à possibilidade de falar, o que dizer, como dizer e a hora de falar ou calar, inscreve-se, assim, em uma ordem discursiva adultocêntrica.

Nas últimas décadas, contudo, houve um processo intenso de disseminação das Tecnologias de Informação e Comunicação (TIC), o que favoreceu o surgimento de novas possibilidades de produção e compartilhamento de conteúdos por crianças em redes como Facebook, YouTube, Instagram, entre outras (COMITÊ..., 2018). Fortemente pautadas por uma cultura visual, tais redes têm potencializado a projeção de crianças e adolescentes nas esferas públicas midiáticas, bem como a reconfiguração de suas culturas infantis, na relação cotidiana que estabelecem com os dispositivos móveis.

No Brasil, nos anos 2015 e 2016 - segundo pesquisa coordenada pelo Media Lab da Escola Superior de Propaganda e Marketing (ESPM) -, dos cem canais mais vistos no YouTube Brasil, houve um crescimento de 36 para 41 dos canais que produzem conteúdo direcionado para crianças de 0 a 12 anos ou consumido por elas (CORRÊA, 2016).

Inseridas em um cenário marcado pela cultura da convergência (JENKINS, 2008), que reafirma a lógica da sociedade do consumo (BAUDRILLARD, 2008), crianças têm sido desafiadas, cada vez mais cedo, a lidar com referências socioculturais para além de seus contextos imediatos, de familiares e amigos (COMITÊ..., 2018). Se, certamente, ainda guardam a condição de aprendizes, também assumem a condição de ensinantes - em alguns casos, influenciando as práticas sociais de milhões de internautas (crianças e adultos).

Atendendo ao convite da plataforma de compartilhamento de vídeos YouTube, expresso no slogan "Broadcast yourself", crianças e adolescentes embarcam na aventura de tornar-se YouTuber-mirins. Segundo dados da Rede Snack, em 2018, dos dez canais mais vistos pelo público infantil, dois eram protagonizados por crianças YouTubers (LAFUENTE, 2018). Um desses canais, Erlânia e Valentina Pontes, já alcançou a marca de mais de 15,5 milhões de inscritos e alguns de seus vídeos superam a marca de 10 milhões de visualizações ${ }^{1}$. 
Nos casos de crianças YouTubers com alta popularidade, como Júlia Silva, Manoela Antelo, Isaac do Vine, entre outros, estamos falando de meninos e meninas cujas performances comunicativas estão fortemente associadas ao universo do consumo, da celebrização, da fama etc. Narram o próprio consumo, brincam de consumir, projetam desejos de consumo (SAMPAIO; CAVALCANTE, 2016).

Desse lugar de quem conquistou, precocemente, a fama, falam a milhões de outras crianças, convidando-as a ingressar num mundo encantado, em que reina a felicidade, a fartura e a beleza. Além disso, em seus vídeos, as crianças assumem, com frequência, a condição de protagonistas na relação com adultos, posicionados como coadjuvantes.

Neste artigo, propomo-nos a problematizar esse lugar de fala e de expressão da criança no YouTube, considerando-o também lugar de exposição pública, que incide sobre um elemento central: o direito à comunicação. Interessa-nos compreender essa experiência infantil sob a ótica dos direitos digitais de crianças e adolescentes (LIVINGSTONE, 2014), consubstanciados nos direitos à proteção, à provisão e à participação, reconhecidos pela Convenção dos Direitos das Crianças, em 1989².

Compreendemos aqui que a plataforma em questão tem, por um lado, características de rede social, mas, por outro, de rede comercial das mais lucrativas, com políticas de monetização pouco transparentes pautadas pela lógica do consumo (MIRANDA, 2017; MARÔPO et al., 2018).

Para alcançar propósito do estudo, optamos por analisar, neste artigo, vídeos de crianças YouTubers extraídos de uma playlist com alta popularidade de canais infantis, sob a denominação "Rico vs Pobre". Num dos países com maior nível de desigualdade social do mundo³, essa playlist nos parece potente para explorar os tensionamentos da participação da criança na vida pública. Afinal, quais são as implicações de sua atuação quanto ao exercício dos direitos digitais de crianças e adolescentes - em especial, os direitos à proteção, à provisão e à participação?

Com o propósito da investigação definido, buscamos caracterizar e contextualizar o fenômeno da playlist "Rico vs Pobre", a fim de alcançar uma visão mais panorâmica dos aspectos mais recorrentes de sua dinâmica. Após análise geral da playlist, os vídeos foram selecionados partindo dos critérios visualizações, curtidas (likes) e protagonismo de meninas e meninos brasileiros. O corpus selecionado para a análise qualitativa foi composto por cinco vídeos: dois protagonizados por meninos; dois, por meninas; e um, por um menino e uma menina. Dado o critério de recorte adotado, alguns vídeos aqui analisados são sequência de outros produzidos pelos mesmos canais.

O corpus foi formado por: "Rico vs Pobre 2", de Isaac do Vine; "Rico vs Pobre Fazendo Amoeba/ Slime \#20", de Piero Start; "Rico vs Pobre", de Erlânia e Valentina Pontes; "Rico e Pobre - Material Escolar", de Bela Bagunça; e "Rico vs Pobre - Voltas às Aulas", de Maria Clara e JP.

Por meio de uma análise crítica do discurso (VAN DJIK, 2008), observamos questões importantes para o debate aqui proposto, como: que construções discursivas permeiam a fala das crianças sobre a dicotomia entre ricos e pobres; que representações visuais de riqueza e pobreza elas projetam; e o que essas narrativas nos dizem acerca da participação infantil nessa rede comunicacional.

Comecemos, então, com um olhar panorâmico do fenômeno.

\section{"Rico vs Pobre": A Desigualdade Social como Mote de Entretenimento}

As playlists integram as opções de classificação e ordenamento de vídeos da plataforma YouTube. Elas possibilitam ao responsável pelo canal criar uma série temática e aos usuários identificar mais facilmente temas de seu interesse. 
Dado o caráter autorreferente das comunicações do YouTube (SAMPAIO; CRAVEIRO, 2019), um vídeo com elevado número de visualizações tende a ser replicado à exaustão em novas versões, tornando longeva a presença de uma série temática na plataforma. As playlists de sucesso, portanto, ajudam-nos a identificar campos temáticos capazes de gerar engajamento.

Esse é o caso da playlist reunida em torno da temática "Rico vs Pobre", que transformou uma das mazelas mais graves do país em um tópico recorrente de entretenimento infantil. O YouTube não fornece um dado quantitativo, mas, utilizando a busca do Google ${ }^{4}$ para os vídeos dessa playlist, mais de 49 mil resultados foram encontrados.

Na definição da playlist também identificamos algumas subdivisões, que incluem apenas a expressão "Rico vs Pobre" ou que lhe conferem maior especificidades, como "Rico vs Pobre Fazendo Amoeba/Slime \#"; "Rico x Pobre no Salão de Beleza e Spa" ou "no Supermercado". Ao observarmos essas subdivisões, percebemos que brinquedos e situações cotidianas relacionadas ao consumo se destacam na composição das comparações.

Produções culturais que fazem esse tipo de comparação não são novidade no audiovisual brasileiro. Desde o quadro "Primo Rico \& Primo Pobre"5, sucesso da Rádio Nacional em 1950, até personagens como Caco Antibes ${ }^{6}$ (Miguel Falabella), no Programa Sai de Baixo, comparações jocosas entre as classes sociais compõem o imaginário nacional, reforçando e/ou pondo em xeque representações sociais cristalizadas (MOSCOVICI, 2009).

Segundo dados divulgados em 2018 pela $\mathrm{Oxfam}^{7}$, o Brasil figura como nono país mais desigual do mundo, com o rendimento médio do $1 \%$ mais rico chegando a ser 36,3 vezes maior que o dos $50 \%$ mais pobres. Apesar da gravidade dessa situação ou, talvez, por causa dela, narrativas de humor sobre a dicotomia ricos e pobres migraram da radiodifusão para a Internet, como é o caso da playlist "Rico vs Pobre" e, de modo especial, dos cinco vídeos escolhidos para análise.

Eles variam em duração e cenas dramatizadas, mas algo que se repete em todos é a solicitação de interação por meio de curtidas e inscrições no canal, bem como a necessidade de explicação de que se trata de um vídeo humorístico, com o qual as pessoas não devem se sentir ofendidas. A apresentação desse alerta, contudo, já evidencia que o conteúdo traz situações sensíveis.

Com duração de 5 minutos e 11 segundos, o vídeo "Rico vs Pobre 2", de Isaac do Vine, começa com o próprio Isaac cumprimentando os seguidores: "Fala, meus anjinhos! Deixando bem claro: esse vídeo é só uma brincadeira, não tem nenhuma discriminação. É só pra vc [sic] dar risada”. São apresentadas cinco cenas: "Se arrumando"; "Acordando"; "Sol”; "Quando 'tem' sorvete"; e "Festa".

No vídeo de Piero Start, com duração de 13 minutos, o rapaz, usando agasalho Ferrari e cabelo bem-penteado, olha pela janela e afirma: "Vamos fazer essa slime logo porque o garotinho pobre passou ali", anunciando, de forma explícita, o que será apresentado ao longo do vídeo, em que se alternam cenas do menino rico e do pobre competindo sobre fazer a maior slime.

Erlânia e Valentina Pontes começam cumprimentado os seguidores: "Hello, meninas e meninos". As duas estão sentadas em um sofá e anunciam o que será exibido durante os 10 minutos e 12 segundos de duração do vídeo. As situações são apresentadas antecedidas por uma cartela. No caso das cenas da pessoa rica, de cada lado da palavra "rico" aparecem desenhados dois maços de dinheiro. Nas cenas protagonizadas por pessoas pobres, são exibidas moedas.

No vídeo da Bela Bagunça, a menina saúda o público e apresenta o tema do vídeo: "Rico vs Pobre - Material Escolar". O vídeo, de 12 minutos e 13 segundos, explora comparativos entre ricos e pobres nas seguintes questões: "Chegando na [sic] livraria"; "Escolhendo caderno"; "Escolhendo lápis e caneta"; "Comprando estojo e mochila"; e "Pagando a conta”. 
No caso de "Rico vs Pobre - Voltas às Aulas", de Maria Clara e JP, o vídeo apresenta as duas crianças protagonistas sentadas, com um cenário virtual de sala de aula. As crianças saúdam o público e se apresentam. No vídeo, são feitos comparativos entre ricos e pobres em algumas situações: "Mãe acordando cedo"; "Se arrumando"; "Material escolar"; "Chegando na [sic] escola"; "Falando o que fez nas férias"; "Comendo merenda na escola"; e "Quando o filho está doente".

\section{"Rico vs Pobre": Disputa de Narrativas}

Como a própria playlist indica, os vídeos são construídos como um campo de disputa de narrativas. Uma mesma situação é colocada a partir de pontos de vista diferentes. Em alguns, a tela é dividida ao meio e o termo "versus" abreviado e apresentado com tipografia típica dos videogames de luta. Os vídeos selecionados apresentam situações cotidianas que podem ou não fazer parte do universo das crianças: compras de roupas, banhos de piscina, compra de materiais escolares, volta às aulas, tomar sorvete etc.

A oposição entre riqueza e pobreza é, ainda, representada pelas vinhetas sonoras que anunciam as situações. As cenas relacionadas à pobreza são antecedidas por músicas em ritmo de funk, enquanto as situações de riqueza são acompanhadas por uma música instrumental suave, com predominância de piano - soando mais elegante e sofisticada.

As crianças aparecem diante da tela interpretando personagens caracterizadas de acordo com as situações encenadas. Perucas, maquiagem e fantasias são alguns dos recursos utilizados, além de elementos de cena que designam os espaços como próprios de pessoas ricas ou pobres. Em vídeos como o de Piero Start e de Erlânia e Valentina, há um apelo significativo à imagem do pobre como alguém descuidado. Dos cinco vídeos analisados, esses dois são os que mais se valem de estereótipos discrepantes.

No vídeo de Piero Start, intitulado "Rico vs Pobre Fazendo Amoeba/Slime \#20", essa disputa se dá pela oposição dentro/fora de casa. O ambiente interno é limpo e arejado, estruturado, com uma criança usando roupa de marca, banhada e bem-penteada. Já o ambiente da rua tem um garoto com cabelo desgrenhado, "monocelha" e chinelos de borracha, enquanto caminha por entre poças de água da chuva ao carregar uma sacola plástica no braço.

O vídeo inicia com um garoto dentro de casa olhando pela janela e apontando para um outro menino do lado de fora. Os dois são apresentados numa relação de antagonismo e rivalidade, estimulada pela produção de uma slime gigante (espécie de massa de modelar gelatinosa e que faz muito sucesso com as crianças). Ambos são interpretados por Piero Start, YouTuber de 9 anos, cujo canal tem 2.858 .883 inscritos ${ }^{8}$.

Variando um pouco do modelo dos demais selecionados para este artigo, os vídeos de Piero contam com uma breve introdução da cena que será dramatizada. Só depois dessa prévia é que o menino se apresenta, solicita as interações de praxe e fala sobre a meta de likes a ser alcançada pelo vídeo - ação comum entre crianças YouTubers. Outro fator de diferença está na apresentação de patrocínio publicitário explícita no vídeo, feita pelo menino e por seu pai - adulto que é o mesmo interlocutor de Piero nas cenas, atuando como mordomo do garoto rico e pai do garoto pobre.

A presença de adultos, aliás, é bastante frequente nos vídeos, quando não presumida. São eles que operam as câmeras, contracenam com as crianças e escrevem roteiros - como acontece com Isaac do Vine, o qual conta com a participação da mãe e do tio na produção dos vídeos ${ }^{9}$. No caso de Piero, o que deveria ser uma presença adulta responsável, em ambas as situações apresentadas, acaba resultando em estímulo ou ajuda no intento de disputa e provocação entre as crianças.

No caso do vídeo do canal Erlânia e Valentina Pontes ${ }^{10}$, com 15.364 .603 inscritos, a presença do adulto se dá pela participação da mãe, Erlânia, que divide a tela com a filha Valentina, de 4 anos. A mãe, na 
verdade, é a protagonista, cabendo a ela o anúncio da temática do vídeo e a solicitação para que a audiência ajude a realizar o desejo de 195.512 mil likes para a gravação e de que o canal atinja 1 milhão de inscritos.

Nas cenas de "Rico comprando roupa", mãe e filha são mostradas bem-arrumadas. Valentina está de cabelo preso e usa uma tiara que combina com o vestido azul-marinho de mangas longas. A mãe, embora não mostre o rosto, exibe relógio, pulseiras e cordões dourados. Na narrativa, conduzida pela mãe, há o incentivo para que a filha escolha livremente o que quiser comprar na loja de roupas infantis. Tal argumento reforça a lógica do consumo pelo consumo, bem como o desejo de ser reconhecido como alguém rico e que, por isso, compra o que quiser, sem criticidade.

Na situação "Pobre comprando roupa", a mãe chega com a filha a uma mercearia de bairro, onde roupas penduradas na parede dividem espaço com sacos de ração e produtos alimentícios. Além do cenário, o signo da pobreza se evidencia pela linguagem da mãe: "Bom dia, dona Graça. Vim comprar umas roupinha pra minha fia[sic]"; "A senhora tem uns conjuntim que dê nela? [sic]". As frases são pronunciadas em um ritmo arrastado em que as vogais são bem prolongadas, numa caricatura do linguajar popular.

Diferentemente da situação anterior, em que mãe e filha escolhem livremente o que comprar, nesse caso, a possibilidade da compra está diretamente associada ao valor dos produtos. Falas como "Vou usar o dinheiro do Bolsa Família” são usadas como demonstração do baixo poder aquisitivo da família, assim como a tentativa de incluir o saco de leite da "cesta básica" para reduzir os custos da transação. Nessa construção discursiva, o pobre aparece associado claramente a uma conduta antiética, corroborando para reforçar críticas às políticas de bem-estar social voltadas para a população de baixa renda.

Em outros vídeos, como o do canal Bela Bagunça, que tem 10.189.96911 de inscritos, outra característica muito explorada é o tom de voz dos adultos, em que surge a dicotomia "Rico de Fala Comedida"/“Pobre que Grita”. O vídeo recorre ao tom exaltado sempre que a mãe da criança pobre nega a compra dos itens desejados. Há a ausência de figura parental junto à criança rica, que aparece em situações de consumo sem quaisquer orientações ou limites. Quando presente, essa figura reitera o verbo "comprar". No caso da menina pobre, a figura materna surge como ente cerceador de desejos. É essa mãe, ainda, que está sempre elevando o tom de voz ao negar tudo que lhe é solicitado, o que reitera a caracterização negativa da pobreza.

Isso também é perceptível no vídeo de Maria Clara e JP, cujo canal tem 12.379.032 $2^{12}$ inscritos. Os pais estão sempre ausentes fisicamente do quadro, representados apenas pela fala, e seu tom de voz vem acompanhado com grosserias e descredibilização da fala das crianças por parte do adulto/pai pobre. Essa atitude contrasta com a gentileza e a amabilidade na fala do adulto na situação de riqueza. Tais construções discursivas se enquadram no que van Djik (2008) trata como autoapresentação positiva e outroapresentação negativa. Existe um reforço de que a imagem socialmente válida e almejada é a da riqueza, da ostentação. O outro, por não se encaixar nesse patamar, pode ser desqualificado e ridicularizado, uma vez que as cenas "engraçadas" ou situações inusitadas acontecem, em sua maioria, com personagens pobres.

No caso do YouTuber Isaac do Vine, cujo canal tem 7.145.385 inscritos ${ }^{13}$ e pelo menos cinco vídeos com a temática "Rico vs Pobre", o menino dramatiza sozinho todos os papéis para demonstrar as diferenças de classe social nas diversas situações encenadas.

A pessoa rica identifica os produtos por onde foram comprados ou pela marca. Já na representação da pobreza, Isaac do Vine usa um cosmético popular, Kolene ${ }^{\varpi}$, no cabelo cacheado e muito assanhado, como produto característico de pessoas pobres. O creme é usado exageradamente e o menino, satisfeito com o resultado, afirma: "Agora vai sair a dureza do meu cabelo" - alusão pejorativa associada ao cabelo crespo.

Importante dizer que, na transição da "cena rica" para a "cena pobre", Isaac do Vine interrompe a gravação para dizer que o "espelho tá muito bonito para ser de pobre", discurso que estabelece uma conexão necessária entre pobreza e feiura. 
Esses são apenas alguns dos elementos discursivos que compõem a dita "brincadeira" infantil, feita para "fazer rir". Se considerarmos que a análise desse artigo se deteve em um corpus reduzido, podemos depreender que a problemática delineada nessa playlist é bem mais grave.

\section{Considerações Finais}

Nos cinco vídeos analisados na playlist "Rico vs Pobre", ainda que as crianças assumam lugar de destaque na condução da narrativa, a participação na cena midiática tende a reproduzir um discurso adulto que reforça preconceitos e estereótipos, em um país fortemente marcado pela desigualdade social. As histórias contadas trazem consigo a incorporação de discursos hegemônicos, que se aproximam de um modelo televisivo tradicional, possivelmente associado ao repertório cultural acessado pelas crianças e suas famílias.

Todos os materiais analisados apresentam uma estrutura narrativa semelhante: fala inicial da(s) criança(s) saudando o público; solicitação de interação com elementos do vídeo (likes, inscrição no canal e comentários); apresentação do tema a ser tratado; e começo das sequências alternadas de situações supostamente passadas por ricos e pobres. Há o uso de vinhetas e cartelas para separar os blocos de conteúdo e, em alguns casos, há ainda separação sonora e anúncios publicitários, que vêm em forma de merchandising promovido pela própria criança. Tais elementos são reveladores da natureza autorreferente desses materiais, submetidos à lógica da padronização, distanciando-os da noção ingênua de autenticidade e/ou de criação genuína.

Apesar do aparente tom de neutralidade adotado pelos vídeos, que ressaltam ser tudo aquilo "apenas uma grande brincadeira", "não ter discriminação" ou que "não é para ofender ninguém", há uma clara construção positiva da imagem do rico e negativa do "pobre. Essa construção se dá, principalmente, na fratura visual que as imagens de pobreza apresentam: são ambientes degradados, desorganizados, com personagens malvestidos, sujos, despenteados e impossibilitados de desfrutar de um mundo de facilidades, somente acessíveis pelo viés financeiro.

Esse lugar "de fala" das crianças, oportunizado pelas novas tecnologias de comunicação, embora tenha potencial para ser um lugar de reverberação de novas narrativas, pautadas por outros valores, está impregnado pela lógica da sociedade do consumo (BAUDRILLARD, 2008), reverberando a onipresença do desejo de compra e orientando-se por um modelo de vida baseado no consumismo como representação do sucesso.

O imaginário nacional acessado pelas crianças pauta-se em representações sociais ancoradas em noções bastante estratificadas de riqueza e pobreza (MOSCOVICI, 2009). É o que se pode observar como elemento de repetição nos vídeos analisados, cujas imagens e expressões se baseiam em um discurso hegemônico, que escancara, para fins de entretenimento, mazelas sociais e preconceitos. Torna-se, assim, recorrente a ênfase no poder de compra como marcador de um estilo de vida supostamente superior. Nesse contexto, crianças aprendem e ensinam o valor do consumo desenfreado e exagerado como forma de pertencimento social.

A presença parental nos vídeos, que poderia servir de mediação e orientação, cumpre papel de estímulo às situações apresentadas, de maneira irrefletida. Assim, o incentivo ao consumo excessivo, à rivalidade entre crianças e à falta de consciência social transparecem. Desse modo, podemos concluir que o exercício do direito à participação, numa rede marcada pela lógica mercadológica e pela pressão pelo reconhecimento público, tem como contraponto o comprometimento de aspectos importantes, relativos aos direitos à provisão e à proteção. 


\section{Contribuições das Autoras}

Conceptualização: Sampaio IV, Pereira GC, Cavalcante APP; Metodologia: Sampaio IV, Pereira GC, Cavalcante APP; Redação: Sampaio IV, Pereira GC, Cavalcante APP.

\section{Notas}

1. Disponível em: https://www.youtube.com/channel/UC0ebPa2q1rwZVN7dYemunUQ. Acesso em: 18 set. 2019.

2. Disponível em: https://www.unicef.org/brazil/convencao-sobre-os-direitos-da-crianca. Acesso em: 18 set. 2019.

3. Disponível em: https://www.cartacapital.com.br/sociedade/o-que-faz-do-brasil-um-dos-paises-mais-desiguais/. Acesso em: 18 set. 2019.

4. Disponível em: https://tinyurl.com/y35es577. Acesso em: 25 set. 2019.

5. Disponível em: http://memoriaglobo.globo.com/programas/entretenimento/humor/balanca-mas-nao-cai/primo-pobre-primo-rico. htm. Acesso em: 25 set. 2019.

6. Disponível em: http://memoriaglobo.globo.com/programas/entretenimento/humor/sai-de-baixo/galeria-de-personagens.htm. Acesso em: 25 set. 2019

7. Disponível em: https://g1.globo.com/economia/noticia/2018/11/26/desigualdade-de-renda-para-de-cair-no-brasil-apos-15-anos-enumero-de-pobres-cresce-aponta-ong.ghtml. Acesso em: 25 set. 2019.

8. $\quad$ Dados de 12 de setembro de 2019.

9. Disponível em: http://g1.globo.com/bahia/noticia/2016/05/fenomeno-na-web-isaac-do-vine-coleciona-milhoes-de-seguidores.html. Acesso em: 07 out. 2019.

10. Dados de 12 de setembro de 2019.

11. Dados de 12 de setembro de 2019.

12. Dados de 12 de setembro de 2019.

13. Dados de 11 de setembro de 2019.

\section{REFERÊNCIAS}

BAUDRILLARD, J. A sociedade de consumo. Portugal: Edições 70, 2008.

COMITÊ GESTOR DA INTERNET NO BRASIL. TIC kids online Brasil 2018: Pesquisa sobre o uso da internet por crianças e adolescentes no Brasil. São Paulo: Comitê Gestor da Internet no Brasil/Núcleo de Informação e Coordenação do Ponto BR, 2019. E-book.

CORRÊA, L. O que tem dentro da caixa? Crianças hipnotizadas pelo YouTube Brasil, as fronteiras entre entretenimento, conteúdo proprietário e publicidade. In: Encontro de Pesquisadores em Publicidade e Propaganda, 7, Rio de Janeiro: PUC-Rio, 2016. 
JENKINS, H. Cultura da convergência. São Paulo: Aleph, 2008.

LAFUENTE, L. Ranking divulga lista dos canais preferidos das crianças no YouTube Brasil. TecMundo, [s. l.], 12 out. 2018. Disponível em: https://www.tecmundo.com.br/internet/135126-ranking-divulga-lista-canais-preferidoscriancas-youtube-brasil.htm. Acesso em: 18 jan. 2019.

LIVINGSTONE, S. Children's digital rights: A priority. Intermedia, London, v. 42, n. 4-5, p. 20-24, 2014.

MARÔPO, L. et al. Meninas no YouTube: Participação, celebrização e cultura do consumo. Estudos em Comunicação, Covilhã, v. 1, n. 26, p. 175-195. 2018. https://doi.org/10.20287/ec.n26.v1.a10

MIRANDA, N. P. Beijos monstruosos e eletrizantes: Os direitos à provisão, à proteção e à participação no canal de Julia Silva no Youtube. 2017. Dissertação (Mestrado em Comunicação e Linguagens) - Programa de Pós-graduação em Comunicação, Universidade Federal do Ceará, Fortaleza, 2017. Disponível em: http:// www.repositorio.ufc.br/handle/riufc/34463/. Acesso em: 10 nov. 2018.

MOSCOVICI, S. Representações Sociais: Investigações em psicologia social. Petrópolis: Vozes, 2009.

SAMPAIO, I. S. V.; CAVALCANTE, A. P. P. (coords.). Publicidade infantil em temos de convergência. Fortaleza: Universidade Federal do Ceará/Instituto de Cultura e Arte/Grupo de Pesquisa da Relação Infância, Juventude e Mídia, 2016. Disponível em: https://www.defesadoconsumidor.gov.br/images/manuais/ publicidade_infantil.pdf. Acesso em: 08 out. 2018.

SAMPAIO, I.; CRAVEIRO, P. Dinâmicas de Participação de Crianças e Jovens YouTubers. In: COLAÇO, V. et al. Juventudes em Movimento: Experiências, redes e afetos. Fortaleza: Expressão Gráfica Editora, 2019.

SPIVAK, G. C. Pode o subalterno falar? Belo Horizonte: Editora UFMG, 2010.

VAN DIJK, T. A. Discurso e poder. São Paulo: Contexto, 2008.

Recebido: 06 Jan. 2020

Aceito: 10 Jul. 2020

Editoras Associadas:

Adriana Laplane e Lucia Reily 